\title{
Updating optics education after the bubble
}

Jay Damask

Jay N. Damask, "Updating optics education after the bubble," Proc. SPIE 9663, Eighth International Topical Meeting on Education and Training in Optics and Photonics, 96630X (6 October 2003); doi: 10.1117/12.2208455

SPIE Event: Eighth International Topical Meeting on Education and Training in Optics and Photonics, 2003, Tucson, Arizona, United States 


\title{
Updating Optics Education After the Bubble
}

\author{
Jay N. Damask \\ 201 West $89^{\text {th }}$ St., Apt 3C, New York, NY 10024 \\ (212)874-3364,damask@alum.mit.edu
}

\begin{abstract}
The patent literature has captured a wealth of optical component developments targeted for telecommunications applications. During the telecom bubble there was no incentive to communicate these advancements. Yet today, such information must be absorbed and disseminated to recalibrate the baseline knowledge of students and professionals.

(C)2003 Optical Society of America

OCIS codes: (000.0000) General
\end{abstract}

\section{Introduction}

The design, engineering, and manufacture of optical components for telecommunications applications made great advances between about 1996 and 2002, funded in large part by placements of private investment in telecom startups as well as elevated stock values used to purchase companies. At the engineering level, these optics startups were driven by market demands for component functionality and economy, forcing in turn a design evolution of old components and development of new components. However, as we all know, the bubble burst two to three years ago and few of the original startups still exist.

During the bubble period there was little incentive to make public advances in component technologies. The goal was to increase the stock price, not write papers. The lack of frank and timely communication has led to a marked slowdown in the dissemination of knowledge and has at times led to a bifurcation of the knowledge base between academic institutions and industry. This author, being on the industry side, has more than once reviewed Journal submissions from academia that were clearly two to three years behind what was known in industry. This is a surprising role reversal from historical norm.

Efficient progress in the field of optics requires that recent developments be communicated. Students and professionals need to know where the new baseline is in order to move forward without duplication. While the companies that developed many technologies have largely disappeared, a wealth of information has been left in the patent literature. The patent literature provides a body of knowledge that is not well referenced in technical literature. Yet patents were used by investors as insurance of their investments in telecom startups, and accordingly were written with a detail that often outstrips what is available in the technical literature.

To cite two examples from the U.S. patent database, while patents for optical isolators and circulators have been issued back to 1981, one-half of all isolator and circulators patents have been issued since 1996 and 1999, respectively. Yet no papers in technical Journals have been published on these two components since 1996 and 1999. For circulators, the patent literature points to two important threads of significant architecture development, the Kafia design and the New Focus design, all in the last six years. Only a few specialists currently know they exist.

\section{Updating Optics Education - A Contribution}

I am writing a monograph entitled, "Birefringent Optics in Telecommunications," to be published by SpringerVerlag in 2004. As a departure from many books on birefringent optics, I am drawing heavily from the patent literature. My goal is to digest the developments made in the last six or so years and decide which avenues proved the most fruitful and elegant. Based on practical architectures of isolators, circulators, Lyot filters, polarizationmode-dispersion generators, and other components, as well as a preliminary foundation of birefringent optics written in the early chapters, I explain the theory underpinning these advances and the reasoning behind the developments. Likewise I am adding information about the applications of these components to provide context for tolerancing. Near impossible tolerances are often the motivating factor to change a particular component architecture. Finally, I am adding all available information on the material properties of the optical elements as a reference.

This book will be successful if it can pull into common knowledge many of the important and interesting practical advances that have happened without fanfare within the last decade. 